Fernando Luiz Barros Edington •

Maria Olívia Amado Ramos Bacellar .

Paulo Roberto Machado · Lúcio Barbosa • Eliana Reis ·

Mitermayer Reis - Mittermayer Barreto Santiago

\title{
Anti-neutrophil cytoplasmic antibodies in leprosy
}

Received: 15 February 2006 / Revised: 2 March 2006 / Accepted: 3 March 2006 / Published online: 3 March 2006

(C) Clinical Rheumatology 2006

\begin{abstract}
Introduction: Anti-Neutrophil Cytoplasmic Antibodies (ANCA) are auto-antibodies directed to intracellular components of neutrophils and used to be considered as present almost exclusively in granulomatous vasculitis. Recently, these auto-antibodies have been found in other autoimmune disorders as well as infectious diseases. Materials and methods: We studied patients with leprosy confirmed by bacilloscopy and/or skin biopsy, in reaction phase from the Ambulatório de Hanseníase do Hospital Universitário Professor Edgar Santos. ANCA and Antinuclear antibodies (ANA) were determined by indirect immunofluorescence using commercially available kits. Results: Twenty patients were enrolled in our study,
\end{abstract}

F. L. B. Edington

Universidade Federal da Bahia,

Salvador, Bahia, Brazil

M. O. A. R. Bacellar

Laboratório de Imunologia do Hospital Universitário Professor Edgar Santos, Universidade Federal da Bahia,

Salvador, Bahia, Brazil

P. R. Machado

Escola Baiana de Medicina e Saúde Pública and Universidade

Federal da Bahia,

Salvador, Bahia, Brazil

L. Barbosa $\cdot$ E. Reis $\cdot$ M. Reis

Fundação Osvaldo Cruz Laboratório de Patologia e Biologia Molecular, Fiocruz,

Salvador, Bahia, Brazil

M. B. Santiago

Escola Baiana de Medicina e Saúde Pública and Serviço de

Reumatologia do Hospital Santa Izabel,

Salvador, Bahia, Brazil

M. B. Santiago $(\bowtie)$

Serviço de Reumatologia do Hospital Santa Izabel. Praça

Almeida Couto,

500, Nazaré,

Salvador, Bahia, CEP 40.000-000, Brazil

e-mail: mitter@svn.com.br nine males and 11 females. The mean age was $36.9 \pm$ 18.2 years. ANCA were present only in one patient, with a perinuclear staining pattern ( $p$-ANCA), and no patient tested positive for ANA. Discussion: Although other studies have shown the presence of ANCA in leprosy, the low frequency of these antibodies in leprosy sera demonstrated in the present study illustrates the high specificity of ANCA for the diagnosis of Wegener granulomatosis.

Keywords Auto-antibodies · Hansen disease - Leprosy · Vasculitis

\section{Introduction}

The interest in studying anti-neutrophil cytoplasmic antibodies (ANCA) emerged in the 1960s, together with the discovery of auto-antibodies detection techniques by indirect immunofluorescence [1]. However, only in the 1980s ANCA started to be used for diagnosis and followup of Wegener's granulomatosis (WG) [1]. Classically, there are two major immunofluorescence staining patterns: (1) c-ANCA, a cytoplasmic predominant one, which correlates with the presence of antibodies against proteinase 3 (PR3) and (2) a perinuclear predominant staining pattern, p-ANCA, which correlates with antibodies directed against other proteins, particularly, myeloperoxidase (MPO). Until recently, ANCA, especially c-ANCA, were thought to be exclusively associated with granulomatous vasculitic syndromes, especially, WG. However, their presence has been demonstrated in other diseases, such as rheumathoid arthritis [2, 3], systemic lupus erythematosus [4], inflammatory bowel disease [5], occupational exposure to silica [6], HIV infection [7], subacute bacterial endocarditis [8], and leprosy [9, 10], suggesting that ANCA could not be so specific for WG as previously thought.

The aim of the present study was to determine the prevalence of ANCA in patients with leprosy in reactive phase, when there is a hyperactivity of the immune system 
with high production of cytokines and polyclonal activation of B lymphocytes.

\section{Material and methods}

We studied patients with leprosy, classified according to Ridley and Jopling criteria [11], confirmed by bacilloscopy and/or skin biopsy from the Ambulatório de Hanseníase do Hospital Universitário Professor Edgar Santos. Patients with concomitant autoimmune disease were excluded from the study. We included only patients with lepra reaction type 1 or 2 , according to the criteria published elsewhere [12]. ANCA were determined by indirect immunofluorescence (IIF) using a commercially available kit (QUANTA Lite ANCA-INOVA) following the protocol summarized below:

The sera to be tested were diluted 1:20 in phosphatebuffered saline (PBS) and incubated on the slides for 30 min in a moist chamber; after this period, the slides were washed with PBS. Again, the slides were incubated in the moist chamber for $30 \mathrm{~min}$, this time with an anti-human IgG conjugate (goat). After washing with PBS, the slides were examined in a fluorescence microscope.

We also tested the sera for the presence of antinuclear antibodies (ANA) by IIF in HEp-2, using a commercially available kit (INOVA).

\section{Results}

Twenty patients were included in the study, 9 women and 11 men, with a mean age of $36.9 \pm 18.2$ years. Half of the patients had lepromatous leprosy (LL) reaction type 2; $37.5 \%$ had borderline leprosy (BL), $80 \%$ of them had type 1 and $20 \%$ had Type 2 reaction; The remaining had tuberculoid leprosy (TL) type 1 reaction. Four patients could not be properly classified. The demographic data and clinical features of the patients are shown in Table 1.

ANCA were present in only one patient, with a perinuclear staining pattern ( $p$-ANCA). No patient had ANA detected in serum.

\section{Discussion}

Leprosy is a chronic infectious disease caused by $M$. leprae. Brazil has the second highest prevalence of leprosy in the world, being responsible for $94 \%$ of the cases diagnosed in the Americas [13]. Prevalence rates vary considerably within the country. About $53 \%$ of registered cases come from the North and North eastern regions, as do $40 \%$ of new cases, according to World Health Organization data. All patients in our study came from Bahia, a state located in the North eastern region of Brazil.

There is a polyclonal activation of B cells in lepromatous leprosy that results in elevated production of different autoantibodies, including rheumatoid factor (RF), ANA, and ANCA $[2,3]$.
Table 1 Demographic data and clinical features of the 20 patients with leprosy

\begin{tabular}{llllll}
\hline Name & Gender & Age & Clinical Form & Reaction type & ANCA \\
\hline MAP & F & 29 & & & $\mathrm{~N}$ \\
IOS & F & 60 & BL & 1 & N \\
MLCS & F & 69 & BL & 1 & N \\
NFS & F & 30 & & & $\mathrm{~N}$ \\
TLS & F & 19 & LL & 2 & $\mathrm{~N}$ \\
MNSR & F & 30 & & & $\mathrm{~N}$ \\
MHCS & F & 50 & BL & 1 & $\mathrm{~N}$ \\
ASO & F & 12 & LL & 2 & $\mathrm{~N}$ \\
AAC & F & 19 & & & $\mathrm{~N}$ \\
AFS & M & 27 & BL & 2 & $\mathrm{~N}$ \\
SPS & M & 29 & LL & 2 & $\mathrm{~N}$ \\
HLLS & M & 14 & LL & 2 & $\mathrm{~N}$ \\
AWFS & M & 42 & LL & 2 & $\mathrm{~N}$ \\
SEM & M & 22 & LL & 2 & $\mathrm{~N}$ \\
NPS & M & 47 & TL & 1 & $\mathrm{~N}$ \\
AS & M & 30 & LL & 2 & $\mathrm{~N}$ \\
GS & M & 73 & BL & 1 & $\mathrm{~N}$ \\
CRH & M & 64 & LL & 2 & p-ANCA \\
JMMJ & M & 33 & BL & 1 & N \\
ESP & M & 39 & TL & 1 & N \\
\hline
\end{tabular}

$F$ Female, $M$ male, $B L$ borderline leprosy, $L L$ lepromatous leprosy, $T L$ tuberculoid leprosy, $N$ negative

Medina et al. [3] studied 64 patients with LL, TL, and BL. They concluded that ANCA may be detected in leprosy, especially $p$-ANCA, as they reported eight patients with $p$-ANCA and two patients with $c$-ANCA, but there was not any association with disease activity or ANCA titers. Freire et al. [14] studied 59 patients with various forms of leprosy and 60 normal individuals. They detected an atypical staining pattern of immunofluorescence $(a$ ANCA) in $28 \%$ of the leprosy patients. No significant correlation with duration of the disease or activity was demonstrated.

More recently, Pradhan et al. [15] searched for the presence of auto-antibodies in 75 patients with LL, BL, and TL and have found $c$-ANCA in $62.5 \%$ of the tested samples, particularly from patients with LL.

Curiously, in our present study, even including only patients with lepra reaction, which, theoretically, would have a higher ANCA positivity because of a hyperactivation of the immune system, we found only one patient with a peri-nuclear staining pattern of ANCA ( $p$ ANCA). Our explanation for such divergence results may rely on the difference in studied populations or, alternatively, methodological differences as the prevalence of ANCA in different clinical situations may also vary depending on the method of cell separation and the experience of the operator. In this regard, we opted by using a well-tested ANCA kit by INOVA.

In conclusion, patients with leprosy in Bahia (Brazil) have a low positivity for c-ANCA. 


\section{References}

1. Wiik A (2002) Rational use of ANCA in the diagnosis of vasculitis. Rheumatology 41(5):481-483

2. Rother E, Metzger D, Lang B, Melchers I, Peter HH (1994) Anti-neutrophil cytoplasm antibodies (ANCA) in rheumatoid arthritis: relationship to HLA-DR phenotypes, rheumatoid factor, anti-nuclear antibodies and disease severity. Rheumatol Int 14(4):155-161

3. Rother E, Schochat T, Peter HH (1996) Antineutrophil cytoplasmic antibodies (ANCA) in rheumatoid arthritis: a prospective study. Rheumatol Int 15(6):231-237

4. Pradhan VD, Badakere SS, Bichele LS, Almeida AF (2004) Anti-neutrophil cytoplasmic antibodies (ANCA) in systemic lupus erythematosus: prevalence, clinical associations and correlation with other autoantibodies. J Assoc Phys India 52:533-537

5. Romas E, Paspaliaris B, D'Apice AJ, Elliot PR (1992) Autoantibodies to neutrophil cytoplasmic (ANCA) and endothelial cell surface antigens (AECA) in chronic inflammatory bowel disease. Aust NZ J Med 22(6):652-659

6. Gregorini G, Ferioli A, Donato F, Tira P, Morassi L, Tardanico R, Lancini L, Maiorca R (1993) Association between silica exposure and necrotizing crescentic glomerulonephritis with pANCA and anti-MPO antibodies: a hospital-based case-control study. Adv Exp Med Biol 336:435-440
7. Hebegger de Sorentino A, Motta P, Iliovich E, Sorrentino AP (1997) Anti-neutrophil cytoplasmic antibodies (ANCA) in patients with symptomatic and asymptomatic HIV infection. Medicina (B. Aires) 57(3):294-298

8. Solo A, Jorgensen C, Oksman F, Noel LH, Sany J (1994) Endocarditis associated with ANCA. Clin Exp Rheumatol 12 (2):203-204

9. Galrão L, Passos LR, Fraife A, Portella C, Andrade N, Santiago M (1997) Moléstia de Hansen mimetizando Granulomatose de Wegener: descrição de um caso. Rev Bras Reumatol 38:96

10. Medina F, Camargo A, Moreno J, Zonana-Nacach A, AcevesAvila J, Fraga A (1998) Anti-neutrophil cytoplasmyc autoantibodies in leprosy. Br J Rheumatol 37(3):270-273

11. Ridley DS, Jopling WH (1966) Classification of leprosy according to immunity. A five group system. Int J Lepr Other Mycobact Dis 34:255-273

12. Foss NT, Souza CS, Goulart IMB, Gonçalves HS, Virmod M (2005) Hanseníase: Episódios Reacionais. Projeto Diretrizes. Associação Médica Brasileira e Conselho Federal de Medicina 3:161-180

13. Araújo MG (2003) Hanseníase no Brasil. Rev Soc Bras Med Trop 36(3):373-383

14. Freire BF, Ferraz AA, Nakayma E, Ura S, Queluz TT (1998) Anti-neutrophil cytoplasmic antibodies (ANCA) in the clinical forms of leprosy. Int J Lepr Other Mycobact Dis 66(4):475-482

15. Pradhan V, Badakere SS, Shankar Kumar U (2004) Increased incidence of cytoplasmic ANCA (cANCA) and other autoantibodies in leprosy patients from western India. Lepr Rev 75 (1):50-56 